\title{
Projected climate impacts to South African maize and wheat production in 2055: a comparison of empirical and mechanistic modeling approaches
}

\author{
LYNDON D. ESTES*†, HEIN BEUKES,$+ B E T H A N Y$ A. BRADLEY $\S$, STEPHANIE R.DEBATS $†$, \\ MICHAEL OPPENHEIMER*ף, ALEXC. RUANE\|, ROLAND SCHULZE** and \\ MARK TADROSS $+\dagger$ \\ *Program in Science, Technology, and Environmental Policy, Woodrow Wilson School, Princeton University, Princeton, NJ 08544, \\ USA, $\dagger$ Department of Civil and Environmental Engineering, Princeton University, Princeton, NJ, 08544, USA, $\$$ Agricultural \\ Research Council, Institute for Soil, Climate, and Water, Stellenbosch, 2599, South Africa, §Department of Environmental \\ Conservation, University of Massachusetts, Amherst, MA 01003, USA, -Department of Geosciences, Princeton University, \\ Princeton, NJ 08544, USA, ||NASA GISS Climate Impacts Group/SSP, 2880 Broadway, New York, NY 10025, USA, **School of \\ Bioresources Engineering and Environmental Hydrology, University of KwaZulu- Natal, Pietermaritzburg, 3209, South Africa, \\ † Climate Systems Analysis Group, University of Cape Town, Rondebosch, 7701, South Africa
}

\begin{abstract}
Crop model-specific biases are a key uncertainty affecting our understanding of climate change impacts to agriculture. There is increasing research focus on intermodel variation, but comparisons between mechanistic (MMs) and empirical models (EMs) are rare despite both being used widely in this field. We combined MMs and EMs to project future (2055) changes in the potential distribution (suitability) and productivity of maize and spring wheat in South Africa under 18 downscaled climate scenarios (9 models run under 2 emissions scenarios). EMs projected larger yield losses or smaller gains than MMs. The EMs' median-projected maize and wheat yield changes were $-3.6 \%$ and $6.2 \%$, respectively, compared to $6.5 \%$ and $15.2 \%$ for the MM. The EM projected a $10 \%$ reduction in the potential maize growing area, where the MM projected a $9 \%$ gain. Both models showed increases in the potential spring wheat production region $(\mathrm{EM}=48 \%, \mathrm{MM}=20 \%$ ), but these results were more equivocal because both models (particularly the EM) substantially overestimated the extent of current suitability. The substantial water-use efficiency gains simulated by the MMs under elevated $\mathrm{CO}_{2}$ accounted for much of the EM-MM difference, but EMs may have more accurately represented crop temperature sensitivities. Our results align with earlier studies showing that EMs may show larger climate change losses than MMs. Crop forecasting efforts should expand to include EM-MM comparisons to provide a fuller picture of crop-climate response uncertainties.
\end{abstract}

Keywords: climate change, crop model, downscaling, DSSAT, empirical, generalized additive model, mechanistic, South Africa, Triticum aestivum, Zea mays

Received 26 October 2012; revised version received 28 June 2013 and accepted 28 June 2013

\section{Introduction}

Climate change impacts focusing on crops should account for several important sources of uncertainty when quantifying the range in potential future effects. The most obvious uncertainty is the extent to which regional precipitation and temperature patterns will change. Most studies address these issues using inputs from climate model ensembles that capture the range of variation in climate trajectories caused by climate model biases and possible emissions trajectories. Another important source of uncertainty is the structural differences between crop models, which has

Correspondence: Lyndon D. Estes, tel. +1 202431 0496, fax +1 609258 2760, e-mail: lestes@princeton.edu started to become an active research focus in the past few years. Crop model uncertainty is the major focus of the Agricultural Model Intercomparison and Improvement Project (AgMIP, Rosenzweig et al., 2013), and has been the focus of several studies (e.g., Palosuo et al., 2011; Tubiello et al., 2007; Rosenzweig \& Wilbanks, 2010; Rötter et al., 2011; Knox et al., 2012).

However, despite this growing awareness of intermodel variation among agricultural impacts researchers, little attention is given to the potentially larger differences between empirical and mechanistic (or process-based) modeling approaches. Multimodel comparisons for crop forecasting compare only mechanistic models (MMs) (e.g., Asseng et al., 2013; Rickebusch et al., 2008; Rötter et al., 2011; Challinor \& Wheeler, 2008; Palosuo et al., 2011), yet both empirical and MMs 
have strengths and weaknesses that should be taken into account.

Ecological impacts researchers have explicitly compared empirical models (EMs) and MMs, providing insight into how these two classes differ (Dormann, 2007; Morin \& Thuiller, 2009; Cheaib et al., 2012; Dormann et al., 2012; Hijmans \& Graham, 2006). These studies found that EMs tend to project larger plant range shifts than MMs (Morin \& Thuiller, 2009; Cheaib et al., 2012), which may be due to EMs' tendency to underestimate persistence under novel climates, or poor ability to simulate plant responses to elevated $\mathrm{CO}_{2}$ (Morin \& Thuiller, 2009; Cheaib et al.,2012). On the other hand, MMs typically do not simulate potentially limiting biotic interactions (e.g., interspecific competition), and thus may understate negative impacts if warming exacerbates such constraints (Morin \& Thuiller, 2009; Tubiello et al., 2007). EMs implicitly incorporate these factors because training data reflect the species' current distribution, which is partly shaped by biotic constraints (Morin \& Thuiller, 2009; Cheaib et al., 2012).

Empirical models thus represent the species' performance within its 'realized' environment, which includes all biotic and abiotic limits, whereas MMs characterize potential performance in response primarily to abiotic factors (Cheaib et al., 2012). For crop species, EMs simulate realized yields in response to prevailing farm conditions (current management, pests, diseases, soil, water, climate), while MMs simulate how potential yields (given existing abiotic conditions) may vary in response to management practices. Given these structural differences, crop EMs and MMs should show climate change responses similar to those found in ecological studies, with EMs showing larger yield (and potential growing region) losses than MMs. Direct comparisons of crops' climate responses simulated by independently developed EMs and MMs are largely absent (but see Lobell \& Burke, 2010; for a comparison of EMs fit to MM-generated data). To date, only a single study of maize compared crop suitability and yield predicted by different modeling approaches, but this work did not project future climate impacts (Estes et al., 2013).

Systematic differences between crop EMs and MMs are apparent when comparing results from different agricultural impacts studies. For example, results for South Africa from several regional-scale impacts studies indicate that maize yields will decline $10-30 \%$ by 2050 (Parry et al., 1999; Jones \& Thornton, 2003; Schlenker \& Lobell, 2010; Knox et al., 2012), wheat yields will be $16 \%$ less by 2030 (Lobell et al., 2008), and overall cereal productivity will fall $0-50 \%$ by 2100 (Parry et al., 2004; Fischer et al., 2005). Among these studies, the two using EMs (Lobell et al., 2008; Schlenker \& Lobell, 2010) projected yield losses that were twice as large (28-30\%) as the two most comparable MM-based results (10-19\%, Jones et al., 2003; Parry et al., 1999; summarized by Schlenker \& Lobell, 2010). Although these differences may be partly due to the low fertilizer inputs used in the MM studies (which would have reduced projected climate sensitivity; Schlenker \& Lobell, 2010), given the food security implications of these findings, and the aforementioned evidence regarding EM-MM discrepancies from the ecological literature, studies directly comparing agricultural impacts projections from these two model classes are needed.

In this study, we compared EM and MM projections of climate change impacts to maize and spring wheat, two important cereals that use different photosynthetic pathways (C4 for maize; C3 for wheat). We focused on South Africa, a regionally and globally important agricultural power that is the world's 9th largest maize producer and sub-Saharan Africa's 2nd largest wheat grower (FAO, 2012). Although it is semiarid, most $(85 \%)$ of South African maize and wheat is rainfed (Hardy et al., 2011). Some climate scenarios show that South Africa will become both drier and hotter (IPCC, 2007), which could cause substantial production losses. We undertook a spatially explicit investigation of how the potential growing areas and productivity of rainfed maize and wheat might be impacted by mid-21st century climate change. Our goal was to examine how crop impacts projections from EMs and MMs differ, while providing further insight into how climate change may impact regional food security.

\section{Data and methods}

\section{Background and model overview}

South African maize is grown primarily in the summer rainfall (ca. $80 \%$ of precipitation between October and April) region in South Africa's northeastern half (Fig. 1), while the bulk of wheat (ca. 50\%) is produced in the year-round and winter rainfall regions (ca. 55-80\% of rainfall between April and September) along the southern and southwestern coasts (Hardy et al., 2011). Maize plantings and production average $31000 \mathrm{~km}^{2}$ and $10000 \mathrm{kt}$, respectively, while wheat extent and production is $8200 \mathrm{~km}^{2}$ and $2300 \mathrm{kt}$, respectively (Anonymous, 2009). Less than $10 \%$ of either crop's production area is irrigated (Bradley et al., 2012).

We simulated future changes in maize and spring wheat yields, as well as shifts in these crops' potential growing regions (hereafter 'suitability'). We used a widely employed mechanistic crop growth simulator (MM) and a simpler EM run with climatological variables. The MM we selected was version 4.5.0.047 of the Decision Support System for Agrotechnology Transfer Cropping System Module (DSSAT-CSM, hereafter 'DSSAT' Jones et al., 2003; Hoogenboom et al., 2012), 


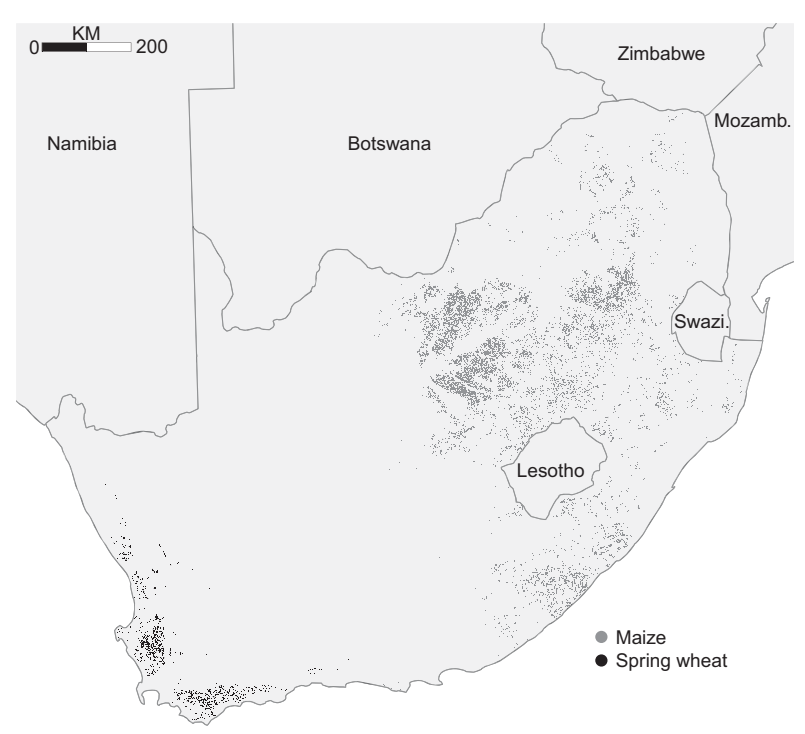

Fig. 1 South African maize and wheat-growing regions. Gray points denote aerial observations (collected between 2006 and 2009) of crop fields growing maize, while black points are fields growing spring wheat (2006-2008).

which incorporates the well-established Crop Environment Resource Synthesis (CERES) maize and wheat models (Ritchie, 1998). DSSAT models simulate growth and reproduction in relation to environmental conditions and management practices (e.g., fertilizer applications, planting densities, cultivar characteristics) at a daily time step (Jones et al., 2003). CERES models simulate potential daily growth (PG) rates using a radiation-use efficiency (RUE) approach:

$$
\mathrm{PG}=\frac{\mathrm{RUE} \times \mathrm{PAR}}{n}\left(1-\mathrm{e}^{-k L A I}\right) \mathrm{CO}_{2}
$$

where PAR is photosynthetically active radiation (MJ m ${ }^{-2}$ day ${ }^{-1}$ ), $n$ is plant density per $\mathrm{m}^{2}, k$ is a light extinction coefficient, LAI is the leaf area index, and $\mathrm{CO}_{2}$ scales growth according to atmospheric $\mathrm{CO}_{2}$ concentrations (Hoogenboom et al., 2012; Ritchie, 1998). The growth rate is further modified by factors (calculated in submodules) related to nitrogen and water stress and temperature and soil fertility, and dry matter is partitioned according to crop growth stage (determined by growing degree days). The $\mathrm{CO}_{2}$ factor, which is the ratio of photosynthetic rates under elevated $\mathrm{CO}_{2}$ relative to reference $\mathrm{CO}_{2}$ levels, was initially derived from chamber experiments, but later updated to reflect Free Air Carbon Enrichment (FACE) experiment results (Rosenzweig \& Iglesias, 1998; Backlund et al., 2008; Boote et al., 2011; Hoogenboom et al., 2012). DSSAT's evapotranspiration module increases water-use efficiency under higher $\mathrm{CO}_{2}$ (via stomatal closure) using a factor derived from the ratios of elevated $\mathrm{CO}_{2}$ to reference transpiration rates (Rosenzweig \& Iglesias, 1998).

We used Generalized Additive Models (GAMs; Yee \& Mitchell, 1991) to develop EMs for maize and wheat. The GAM is a variant of the generalized linear model that can accommodate complex nonparametric relationships between each predictor and the dependent variable, and takes the form:

$$
\mathrm{g}(\mathrm{y})=\beta_{0}+\mathrm{s}_{1}\left(x_{1 i}\right)+\mathrm{s}_{2}\left(x_{2 i}\right)+\ldots+\mathrm{s}_{j}\left(x_{j i}\right)
$$

where $\mathrm{g}$ is a link function allowing nonlinear relationships between the dependent variable $y$ and predictors $X_{1-j}, \beta_{0}$ is the intercept parameter, and $\mathrm{s}_{1-j}$ are optional smoothing functions that can be replaced by linear terms (in which case $s$ is replaced by $\beta$ Yee \& Mitchell, 1991). GAMs are widely used in ecology, can be fit to both binary and continuous response variables, and perform well in estimating current South African maize productivity and distribution (Estes et al., 2013).

In this study, we examined the relative changes in productivity and suitability between the periods 1979-1999 ('the baseline') and 2046-2065 ('the future'), as projected by the two different models developed for each crop, based on input from an ensemble of downscaled climate scenarios.

\section{Datasets}

Crop productivity and distribution data. To develop and validate our models, we used two remote sensing datasets. The first was airborne crop census data from 2006 to 2009, together with accompanying crop field boundary maps (Fourie, 2009; $\mathrm{SiQ}$, 2007). The second was 16 day normalized difference vegetation index (NDVI) imagery collected by the Moderate Resolution Imaging Spectrometer (MODIS; source: http://lpdaac. usgs.gov) for 2006-2009. These two datasets, respectively, provided distribution points (14 736 for maize; 1355 for wheat) and proxy yield variables for the two crops, the development of which is described by Estes et al. (2013) for maize. We summarize these methods here (see Appendix S1) and extended them to spring wheat. We used the crop census points to select NDVI time series (for the year the census observation was made) that were primarily composed of either maize or wheat reflectances, and integrated the NDVI values over the growing season to create a remotely sensed estimate of each crop's yield ('NDVI ${ }_{\text {yield }}$ '). After averaging points to a $20 \mathrm{~km}$ resolution (to minimize site-specific and interannual variability), there were $436 \mathrm{NDVI}_{\text {yield }}$ values for maize and 122 for wheat.

We developed the $\mathrm{NDVI}_{\text {yield }}$ dataset because reported yields were only available for South Africa's provinces, which have a mean area of $135646 \mathrm{~km}^{2}$. Although the provincial data could have been used in a panel modeling approach to estimate crops' climate responses (by incorporating both the interannual and the interprovincial variation in yields; Lobell \& Burke, 2010), we wanted to model yields at a scale that was closer to the resolution of our input soil and baseline climate datasets $\left(\leq 135 \mathrm{~km}^{2}\right)$. We thus used $\mathrm{NDVI}_{\text {yield, which (when }}$ aggregated to the provincial scale) explains 59-67\% of variance in reported yields. Other studies also confirm that this measure is an effective maize yield proxy (see Estes et al., 2013 for citations and Appendix S1). For wheat, there were insufficient observations to robustly assess the proxy against provincial reported yields (Appendix S1), but NDVIderived wheat yield estimates have been effective for other regions (e.g., $R^{2}=0.64$ in Wang et al., 2005; and see Ren et al., 2008).

The $20 \mathrm{~km}$ aggregates of $\mathrm{NDVI}_{\text {yield }}$ were used for training and testing the GAM maize and wheat models, and to assess 
the accuracy of DSSAT baseline yields. The crop census data were used to create the crop suitability maps (see below).

Soil data. Decision Support System for Agrotechnology Transfer requires data describing soil drainage rate, horizon depth, wilting point (WP), field capacity (FC), saturated moisture content, bulk density, and organic carbon content. Estes et al. (2013) mapped these values by applying pedotransfer functions to soil texture and composition data from South Africa's Land Type database (SIRI, 1987), which we used here to run DSSAT maize and wheat. We used a subset of these to fit GAM models [FC, WP, plant available water (FC minus WP), soil depth, and organic carbon; see Appendix S1].

Climate data. For the baseline, we obtained daily values of rainfall, minimum and maximum temperature $\left(T_{\min }, T_{\max }\right)$, and solar radiation from the South African Quinary Catchment database (Schulze \& Horan, 2010), which has a 50 year, spatially and temporally rectified weather record linked to 5838 river basins (mean area $135 \mathrm{~km}^{2}$ ) covering South Africa, Lesotho, and Swaziland.

For the future period, we used an ensemble of 9 Coupled General Circulation Models (CGCMs; see Appendix S2 for list) run under both a relatively high (A2) and low (B1) emissions scenario (Nakicenovic \& Swart, 2000). This allowed us to account for uncertainties related to the future emissions trajectory as well as the simulated atmospheric response. CGCMs provide coarse resolution (200-300 km) climate change estimates, but crop impacts studies typically require higher resolutions. We downscaled the CGCMs to the Quinary Catchment resolution using an empirical method based on self-organizing maps (Hewitson \& Crane, 2006). This technique (summarized in Appendix S1) provides realistic precipitation values that are more consistent with observed patterns in South Africa than those generated by the 'parent' CGCMs (Hewitson \& Crane, 2006), and was shown to provide consistent results between CGCMs across Africa in the IPCC 4th assessment report (Christensen et al., 2007). The method has been used extensively to downscale climate in southern Africa (Crespo et al., 2010; Patt et al., 2010; Tadross et al., 2009).

While the resulting rainfall simulations were more realistic and consistent (Hewitson \& Crane, 2006), the downscaled climate data were still subject to CGCM-specific biases. To remove the remaining discrepancies between the observed baseline weather records and the downscaled CGCM baselines, we adjusted the distribution parameters of the daily records. We first calculated the monthly climatological anomalies between each downscaled CGCM baseline-future pair, and used these to adjust the distribution parameters for $T_{\min }$, $T_{\text {max }}$, and daily rainfall, as calculated for each month in the 20 year baseline record (i.e., the climatologies of the observed baseline). We altered the mean and SD of $T_{\min }$ and $T_{\max }$, and the mean and the shape and scale parameters of the gamma distribution fit to observed rain days. We also altered the number of rain days to match the change in rainfall frequency reflected in each CGCM baseline-future pair. The shape of the cumulative distribution function for each variable for each month was then iteratively adjusted until its summary statistics matched the adjusted statistics, within a specified error tolerance $\left(0.3{ }^{\circ} \mathrm{C}\right.$ for mean $T_{\max }$ and $T_{\min }$ and $0.05 \mathrm{~mm}$ for mean daily rainfall, 0.1 for SDs and 0.075 for gamma shape and scale).

The procedure transformed the baseline weather data into bias-corrected, future daily values for $T_{\min }, T_{\max }$, and rainfall for each of the 18 downscaled CGCMs. Solar radiation was unadjusted except where rain days were adjusted, in which case it was either reduced by $10 \%$ (baseline dry days converted to future rain days) or increased by $10 \%$ (baseline rain days converted to future dry days). We evaluated the procedure's accuracy based on the root mean squared error between the summary statistics derived from the (i) monthly climatologies of the bias-corrected future daily records; and (ii) the observed baseline climatologies that were initially adjusted by the CGCM control-future anomalies (see Appendix S1).

The bias-corrected daily records were used to run DSSAT. For the GAMs, we calculated the following climatological variables from the bias-corrected daily data: average cumulative growing season precipitation, the mean maximum $T_{\max }$ and the mean minimum $T_{\min }$ of the coldest and hottest months in the growing season (where seasons 243 are October-April for maize and May-September for wheat Bradley et al., 2012; Estes et al., 2013). The median projected changes in growing season precipitation (both summer and winter) and maximum $T_{\max }$ are illustrated in Fig. 2. The downscaled precipitation results contrast with the IPCC AR4 ensemble mean, which projected reduced daily mean precipitation for the whole country by 2080 (IPCC, 2007).

\section{Model development and validation}

Mechanistic models. The DSSAT model simulates crop responses to both environmental (described above) and management variables. The key management variables relate to planting (row spacing, plant density, sowing date), fertilization, and cultivar selection (Jones et al., 2003). We used industry recommendations and national cultivar trial data to define these parameters for both crops. Estes et al. (2013) describes the management parameter development for maize, and the sources and derivation steps for wheat parameters are detailed in Appendix S2. Planting density for both crops was determined using simple linear relationships found between mean annual rainfall (MAR) and data from the aforementioned source material. Row spacing was fixed at $25 \mathrm{~cm}$ for wheat and varied with rainfall for maize (between 0.9-2.1 m). Planting occurred automatically for both crops within specified date ranges when plant available moisture exceeded $70 \%$. The date range was May 5th to June 25th for wheat. For maize, we determined an average planting date linked to MAR (from cultivar trials), and automatic planting occurred up to 2 weeks prior to this date and as late as January 15th. For both crops, $32 \mathrm{~kg} \mathrm{ha}^{-1}$ of Nitrogen fertilizer was applied at planting. For maize, we also ran the model with $59 \mathrm{~kg} \mathrm{ha}^{-1} \mathrm{~N}$ to test how higher rates impact model performance, given that average 
fertilization practices are potentially higher than the selected level (see Appendix S2 for $\mathrm{N}$ input details).

The DSSAT model uses coefficients to represent the environmental responses of different crop cultivars (Jones et al., 2003). Ideally, these coefficients should undergo site-specific calibration, but in practice, the required data are rarely available. We applied previously used maize coefficients (Estes et al., 2013) representing a generic short-medium season cultivar. For wheat, we selected coefficients for an Australian cultivar (Appendix S2) grown in climates similar to that of South Africa's spring wheat-growing region.

To run DSSAT spatially, it was necessary to define fields representing unique climate-soil combinations. Merging the soil and climate units (defined by the Quinary Catchment boundaries) created 107,140 'fields' with a mean area of $11 \mathrm{~km}^{2}$. We ran simulations for both crops for each year in the 1979-1999 period, averaged yields over this period, and aggregated results into $923 \mathrm{~m}$ resolution grids (to compare with the GAMs). We evaluated the accuracy of DSSAT's simulated yields based on the strength of their correlations with $\mathrm{NDVI}_{\text {yield }}$.

We constructed binary suitability maps for the two crops using thresholds of simulated yield and its coefficient of variation $(\mathrm{CV}$, the $\mathrm{SD}$ of yields simulated over the 20 year period divided by the mean annual yield and converted \%). Areas with mean yields above the yield threshold and yield $\mathrm{CV}$ s below the $\mathrm{CV}$ threshold were classed as suitable, while areas with one or both of these values on the other side of its threshold were unsuitable. Thresholds were found using the crop census observations and an equal number of randomly selected, pseudoabsence points placed outside the relevant crop growing regions to extract simulated yield and yield CV values. Thresholds for yield and yield CV were selected based on their ability to maximize the number of true positives (census points) and true negatives (pseudoabsences). The accuracy of the resulting binary suitability maps was assessed against observed suitability surfaces created by creating kernel density estimates of mapped crop fields within the extent of each crop's growing area as defined by the aerial census data [see Estes et al. (2013) and Appendix S2 for further details on this and the calculation of thresholds].

Empirical models. We adapted the approach developed by Estes et al. (2013) to fit and validate GAMs for the two crops. We used $\mathrm{NDVI}_{\text {yield }}$ as the response variable $(n=436$ for maize, 122 for wheat), and the predictors were mean total growing season precipitation, and the average minimum and maximum temperatures of the coldest and hottest month in the growing season (October-April for maize, May-September for wheat Bradley et al., 2012; Estes et al., 2013). To allow for more realistic drought sensitivity, we also included the soil variables described above. In fitting GAMs, we applied smoothing functions to predictors exhibiting nonlinear relationships with the response variable, provided that the smoothing function significantly improved the model fit (Wood, 2001) and had a biologically meaningful interpretation. We discarded variables that were redundant or did not explain a significant proportion of variance in the response variable.

We used 10-fold cross-validation to assess the accuracy of GAM-predicted yields and robustness of the selected model structures. To create suitability maps from the GAM-predicted maize and wheat yields, we used the same
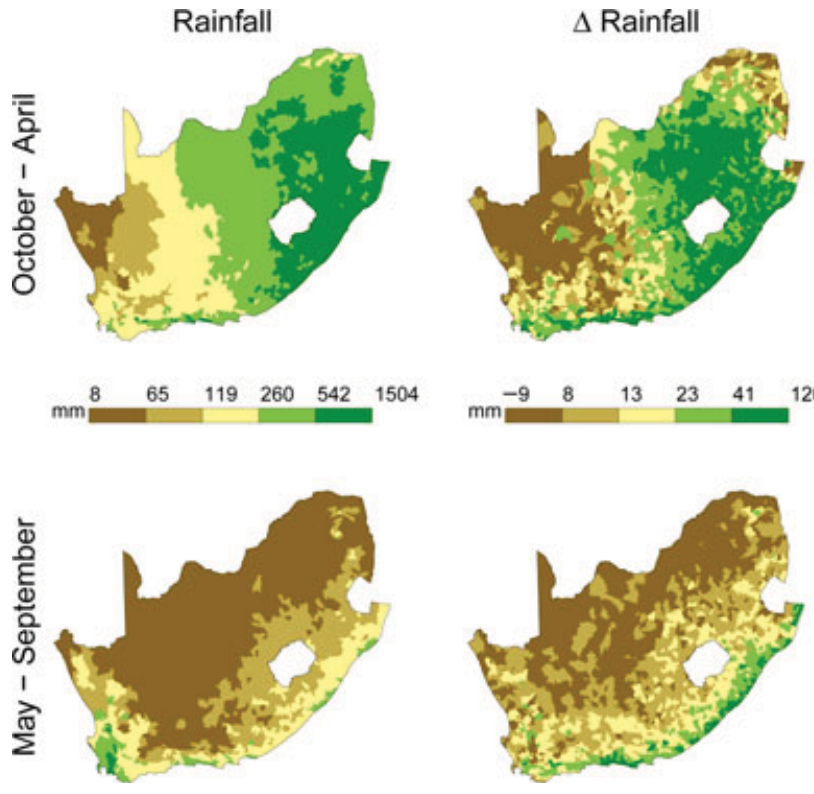
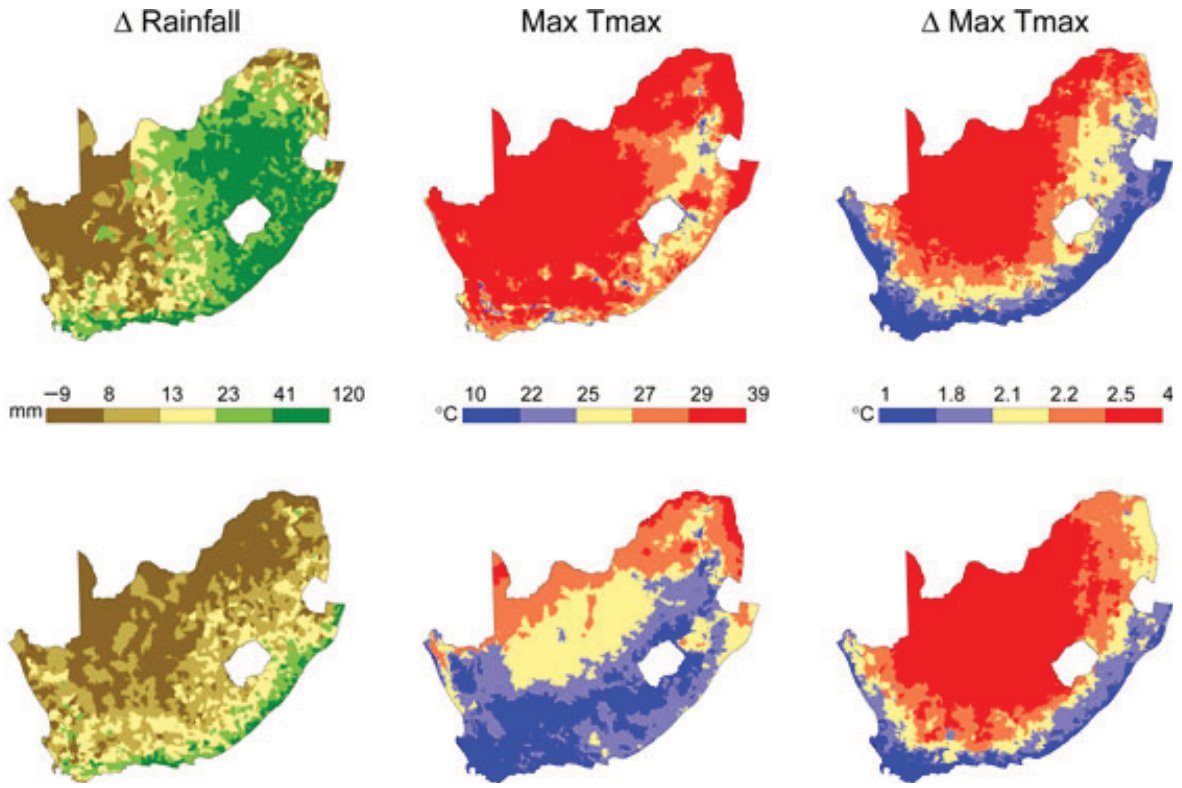

Fig. 2 Baseline (1979-1999) climatologies and their median projected anomalies derived from the bias-corrected results of the 18 downscaled climate scenarios. The left column shows the mean precipitation falling in the summer (October-April, top) and winter (May-September, bottom) halves of the year, and the second column displays median projected rainfall changes. The third column illustrates each season's mean maximum $T_{\max }$, and the fourth column shows the projected changes in this variable. 
thresholding procedure described for DSSAT minus the yield CV threshold, as the GAMs did not produce annual yield estimates.

Crop projections. Each crop model was run with the 18 bias-corrected climate scenarios. DSSAT models can directly simulate the effect of differing $\mathrm{CO}_{2}$ concentrations on crop growth and reproduction, whereas the GAMs cannot. For DSSAT, we set future $\mathrm{CO}_{2}$ levels to 548 or $493 \mathrm{ppm}$, the respective means of the SRES A2 and B1 emissions scenarios for 2046-2065. To examine DSSAT's sensitivity to elevated $\mathrm{CO}_{2}$, we also ran each set of future scenarios with DSSAT's $\mathrm{CO}_{2}$ inputs set to the baseline level. To test how much DSSAT's automatic (i.e., adaptive) planting methods affected crop yield projections, we ran each crop model using the climate scenario that projected the median future rainfall for that crop's growing season, while keeping the planting dates fixed to those used in the baseline simulation. To assess how higher fertilizer application rates impact maize yields under future climates, we used the same climate scenario selected for the planting date analysis and ran DSSAT with $59 \mathrm{~kg} \mathrm{ha}^{-1}$ of $\mathrm{N}$.

We applied a post-hoc adjustment to GAM yield projections to simulate increased photosynthetic and reduced transpiration rates under elevated $\mathrm{CO}_{2}$, following Pongratz et al. (2012). We increased GAM wheat yields by $13 \%$, which we estimated using FACE experiment results reported by Ainsworth et al. (2008) [we found the mean yield increase $(14.25 \%)$ and the mean $\mathrm{CO}_{2}$ increase (184 ppm) and rescaled this to the mean $\mathrm{CO}_{2}$ increase for our study (173 ppm)]. For maize, FACE experiments suggest that it remains unclear how much elevated $\mathrm{CO}_{2}$ enhances the photosynthetic rate of $\mathrm{C} 4$ crops, but reduced transpiration rates under higher $\mathrm{CO}_{2}$ may increase yields by lowering water stress (Leakey, 2009; Kimball, 2011). To account for this effect, we increased GAMprojected maize yields by 5\% [proportional to Pongratz et al's. (2012) multiplier].

To evaluate changes in crop suitability, we created binary suitability maps from each simulated future yield (and yield $\mathrm{CV}$, for DSSAT) surface. We found the fraction of suitability maps agreeing regarding future suitability $(n / 18)$, and used the median fraction (0.5) to assess the projected change in suitability. To assess climate impacts to productivity, we found the median future yield for each crop and calculated the percent change relative to baseline yield. We compared projected yield changes between models within the area shared by both models' baseline and future suitabilities.

\section{Results}

\section{Baseline simulations}

DSSAT's simulated baseline maize yield explained $37 \%$ of spatial variance in $\mathrm{NDVI}_{\text {yield }}$ (Estes et al., 2013; Appendix S3). DSSAT maize yield aggregated to the provincial scale was strongly correlated with, but systematically underestimated, both mean reported provincial yields $\left(R^{2}=0.66\right)$ and aggregated NDVI $_{\text {yield }}$
$\left(R^{2}=0.72 ;\right.$ Appendix S3). Running the model with higher $N$ (59 kg ha ${ }^{-1}$ ) did not appreciably alter the relationship between simulated yields and $\mathrm{NDVI}_{\text {yield }}$ $\left(R^{2}=0.37\right)$, and resulted in a slightly poorer correlation with provincial yields $\left(R^{2}=0.58\right)$, although the bias toward yield underestimation was slightly reduced (Appendix S3). DSSAT's simulated baseline wheat yield explained $40 \%$ of spatial variance in $\mathrm{NDVI}_{\text {yield }}$ (Appendix S3). There were insufficient observations to assess provincial-scale correlations for DSSAT wheat.

The best fitting GAM maize model included nonparametric relationships with mean summer precipitation and WP and linear relationships with mean maximum $T_{\max }$ and soil depth. The selected wheat GAM model had nonparametric terms for average winter precipitation, mean minimum $T_{\min }$, and $\mathrm{WP}$, and a linear term for mean maximum $T_{\text {max }}$. The maize GAM's 10-fold cross-validation had average $R^{2}$ values of 0.66 and 0.64 for the training (the $\mathrm{NDVI}_{\text {yield }}$ values used to fit the model) and test partitions (the excluded $\mathrm{NDVI}_{\text {yield }}$ values), respectively, while the wheat GAM had mean $R^{2}$ values of 0.73 and 0.57 for training and testing, respectively (Appendix S3).

Both DSSAT and GAM's maize suitability showed similar total accuracy (true positives + false positives divided by total area) when compared to the observed maize suitability surface (87\% and $86 \%$; Appendix S3). The DSSAT suitability map was created using a yield threshold of $933 \mathrm{~kg} \mathrm{ha}^{-1}$ and a yield CV threshold of $109 \%$, while a yield threshold of $2957 \mathrm{~kg} \mathrm{ha}^{-1}$ was used for the GAM suitability map.

The wheat suitability maps for the two models also showed comparable accuracy (95\% for DSSAT and 93\% for GAM; Appendix S3), but these statistics were inflated by the large size of the area unsuitable for spring wheat $\left(115000 \mathrm{~km}^{2}\right)$ relative to the potential production region $\left(5200 \mathrm{~km}^{2}\right)$, and the fact that both models correctly classified most of the unsuitable area (negative predictive performance $\geq 0.98$ ). However, both models substantially overestimated spring wheat suitability and thus had low positive predictive power (or precision; 0.46 for DSSAT, 0.33 for GAM). The GAM's false positive error extended up to the length of South Africa's east coast (Appendix S3). The suitability thresholds for DSSAT were $1150 \mathrm{~kg} \mathrm{ha}^{-1}$ for yield and $70 \%$ for yield CV, and the GAM threshold was $1433 \mathrm{~kg} \mathrm{ha}^{-1}$ (Appendix S3).

\section{Projections}

Suitability. Both DSSAT and GAM projected that the core maize growing region will remain suitable in 2055 (Fig. 3), based on the criterion of $\geq 50 \%$ model 
agreement. However, the direction of suitability changes differed between models: DSSAT projected a 9\% gain in suitability, primarily along the southwestern boundary of the baseline growing region, whereas the GAM showed a $10 \%$ loss concentrated along the western and northern boundaries (see Appendix S4 for suitability changes under different agreement fractions).

Both models showed an expansion in the total area suitable for wheat, with the GAM projecting expansion twice as large as DSSAT's (48\% vs. 20\%, Fig. 3). There was little loss projected by either model for its baseline region of suitability, although GAM showed small contractions in the extreme northwest. DSSAT showed suitability expanding into the interior from the northwest and southeast of the current growing region, whereas GAM showed gains into the interior along the entire length of its baseline suitability region (Fig. 3).

To assess the sensitivity of DSSAT's suitability projections to $\mathrm{CO}_{2}$, the simulations run with future climate scenarios, but under baseline, atmospheric $\mathrm{CO}_{2}$ concentrations were also converted to suitability maps. For maize, the median future suitability fraction showed a $4 \%$ suitability loss and for wheat, a $3 \%$ gain. DSSAT therefore showed positive $\mathrm{CO}_{2}$ effects of $13 \%$ and $17 \%$ for maize and wheat, respectively, in response to a projected mean $\mathrm{CO}_{2}$ increase of ca. $170 \mathrm{ppm}$ (the mean projected increase across the A2 and B1 scenarios relative to the mean baseline concentration; see Appendix S4 for further details).

Projected productivity. The maize productivity patterns simulated by the two models were substantially different (Fig. 4). DSSAT's baseline yield maps showed marked variation in response primarily to rainfall, with the highest yields $\left(>4500 \mathrm{~kg} \mathrm{ha}^{-1}\right)$ in the wetter, cooler highlands (Fig. 2) southwest and northeast of Lesotho (Fig. 4). Yields were typically $>50 \%$ lower throughout the rest of the growing region. This spatial pattern in future projected yields was largely unchanged, but there were yield gains through much of the potential growing region. Gains were most pronounced (exceeding 200\%) to the South of Lesotho, and in the high yield areas along the escarpment to the north of Lesotho, and extending from there to the northwestern interior (Fig. 4). On the east coast, yield was projected to rise by $\sim 25 \%$, likely due to less warming $\left(<1.8^{\circ} \mathrm{C}\right.$ increase in $\left.T_{\max }\right)$ coupled with increased rainfall (>41 mm; Fig. 2). Yield losses of up to $25 \%$ were projected in a belt extending from the northwestern boundary of Lesotho to the westernmost extreme of the maize growing region, with several small patches shows losses of 25-50\%. Smaller yield losses (not exceeding 10\%) were projected for the band lying along Lesotho's eastern border, and to the northwest of Swaziland (Fig. 4).

In contrast, GAM's spatial yield patterns, both in terms of simulated potential and percent change, were more uniform than DSSAT's. GAM's highest potential areas corresponded to DSSAT's, and were of similar magnitude $\left(>4500 \mathrm{~kg} \mathrm{ha}^{-1}\right)$, but the high yield areas were larger, and there was smaller range in yields and a more normal distribution of yield classes (Fig. 4). The GAM model projected uniform yield losses of up to $10 \%$ throughout most of the growing region, reaching as high as $25 \%$ in the extreme west and north. Small gains $(<10 \%)$ were projected for a few patches along the east coast and on the escarpment near Lesotho.

Comparing the two models' projected yield changes within their jointly suitable areas, DSSAT's median projected maize yield change was $+6.5 \%$ (interquartile range $=-2.3$ to $18.1 \%$ ), while $\mathrm{GAM}^{\prime}$ 's was $-3.6 \%$ (interquartile range $=-6.0$ to $-2.1 \%$ ).

The baseline wheat productivity patterns projected by DSSAT and GAM generally agree, with both models showing the highest yields $\left(>2600 \mathrm{~kg} \mathrm{ha}^{-1}\right)$ in the current core of the spring wheat production region in the southwestern Cape, and to a lesser extent in a narrow strip along the southern coast (Fig. 5), the two regions with the greatest winter rainfall (Fig. 2). However, the two models' projected yield change patterns diverged considerably. DSSAT showed an eastwards shift in productivity, with yields increasing by $25 \%$ or more along the southern coast, and ranging between $+10 \%$ and $-10 \%$ on the west coast. The GAM projected small losses along the western and southern coasts balanced by strong increases $(\geq 50 \%)$ into the interior of these regions. The east coast where GAM falsely showed baseline suitability was also projected to show some gains (Fig. 5). In the two models' jointly suitable areas, DSSAT's median projected wheat yield change was $+15.2 \%$ (interquartile range $=+6.5$ to $19.7 \%$ ), while GAM's was $+6.2 \%$ (interquartile range $=-2.6$ to $39.6 \%$ ).

We assessed the $\mathrm{CO}_{2}$ sensitivity of DSSAT's projected yield change estimates by comparing the median yield change from simulations conducted under projected $\mathrm{CO}$ concentrations with the median of simulations run under baseline $\mathrm{CO}_{2}$ levels. For maize, there was a positive $\mathrm{CO}_{2}$ effect of $15.7 \%$, and for wheat, the effect was $+26.8 \%$ (see Appendix S4 for further sensitivity results). For planting date sensitivity tests, we reran DSSAT models with MRI A2 scenario for maize and CSIRO B1 for wheat (the respective median rainfall scenarios) with planting dates fixed to those used during the baselines simulations, and compared yields with the initial projections within the area of baseline suitability. Maize planting occurred 5.6 days earlier when planting was automatic, but yields were $14.8 \mathrm{~kg} \mathrm{ha}^{-1}$ lower on 

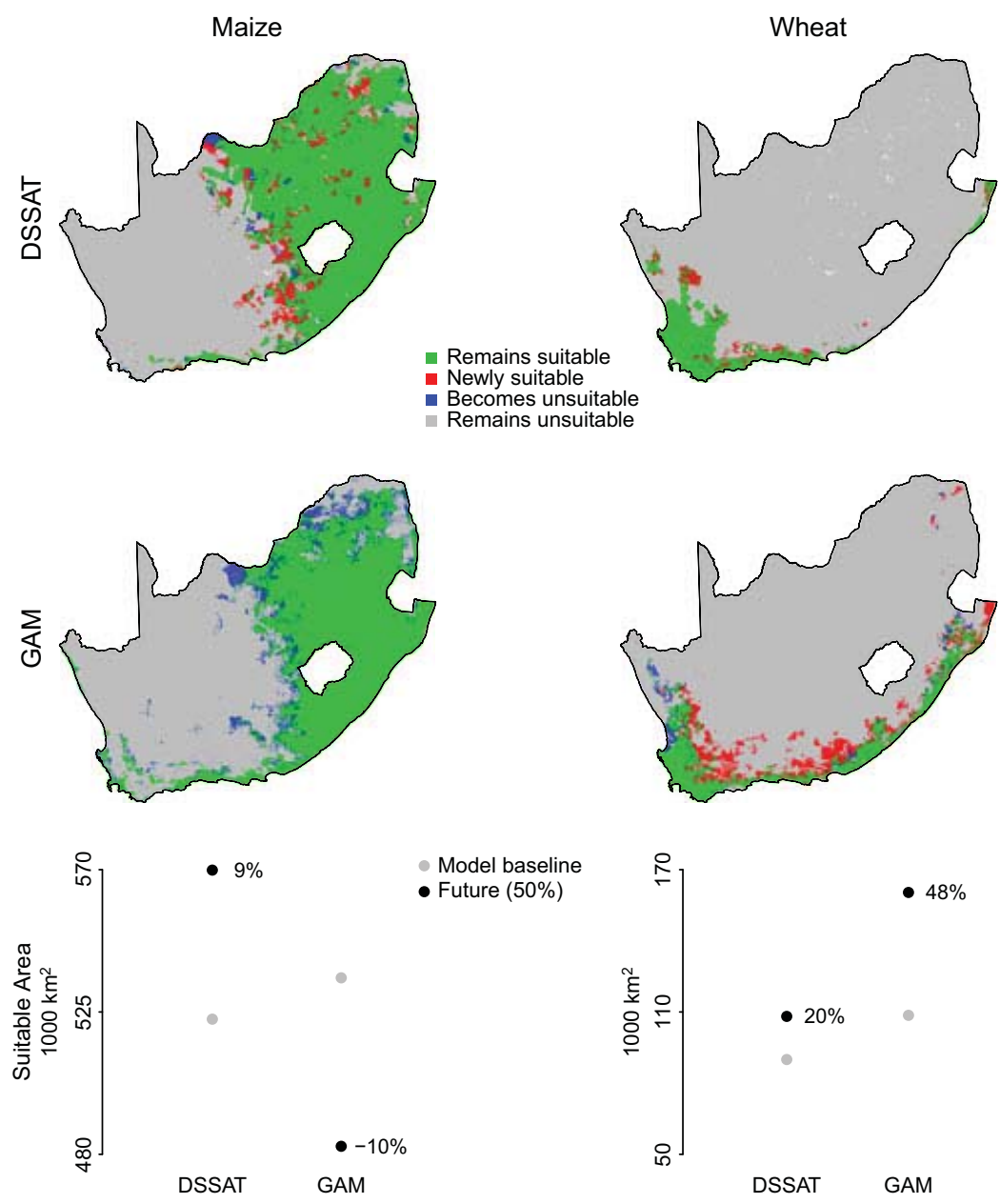

Fig. 3 The change in areas suitable for maize and spring wheat production in 2055, as projected by both the Decision Support System for Agrotechnology Transfer (DSSAT) and Generalized Additive Model (GAM) models under the median agreement criterion (at least 9/18 simulations agree regarding future suitability). Plots along the bottom row show the percent change in suitable area (given in $\left.\mathrm{km}^{2} \times 1000\right)$ relative to each model's simulated baseline suitability.

average compared with fixed planting dates. For wheat, planting was 0.6 days earlier, and yields were $4.7 \mathrm{~kg} \mathrm{ha}^{-1}$ lower. For the maize $\mathrm{N}$ sensitivity test, we reran DSSAT maize under the MRI A2 scenario with $59 \mathrm{~kg} \mathrm{ha}^{-1} \mathrm{~N}$, which showed a median yield change (relative to its baseline) of $+19 \%$, compared to $+13.8 \%$ for the same scenario run with $32 \mathrm{~kg} \mathrm{ha}^{-1}$. The spatial pattern of yield change under higher $\mathrm{N}$ was the same or more positive in $82 \%$ of the maize growing region, and in a further $13 \%$ the projections were at most $3.1 \%$ lower than the original treatment's results (Appendix S4).

\section{Discussion}

\section{Empirical vs. mechanistic models}

Similar to a previous assessment (Estes et al., 2013), the GAMs' baseline yield and suitability estimates were more accurate than DSSAT's, except in delineating the spring wheat suitability region. The better performance and the lower input data requirements suggest that simple EMs such as GAMs can be better choices than data intensive MMs for studying current crop-climate relationships over large spatial extents (Estes et al., 2013).

However, in terms of understanding crop responses to changing climates, the GAMs consistently projected larger yield and suitability losses than DSSAT. DSSAT models projected net productivity and suitability gains, driven by increasing yields in the east of both crops' current growing regions (Figs 4 and 5). GAMs showed either modest yield losses or smaller yield gains than DSSAT in these areas. The exception to this pattern was GAM's large spring wheat suitability gains (driven by limited model calibration data, see Caveats section below), caused by large projected yield increases 

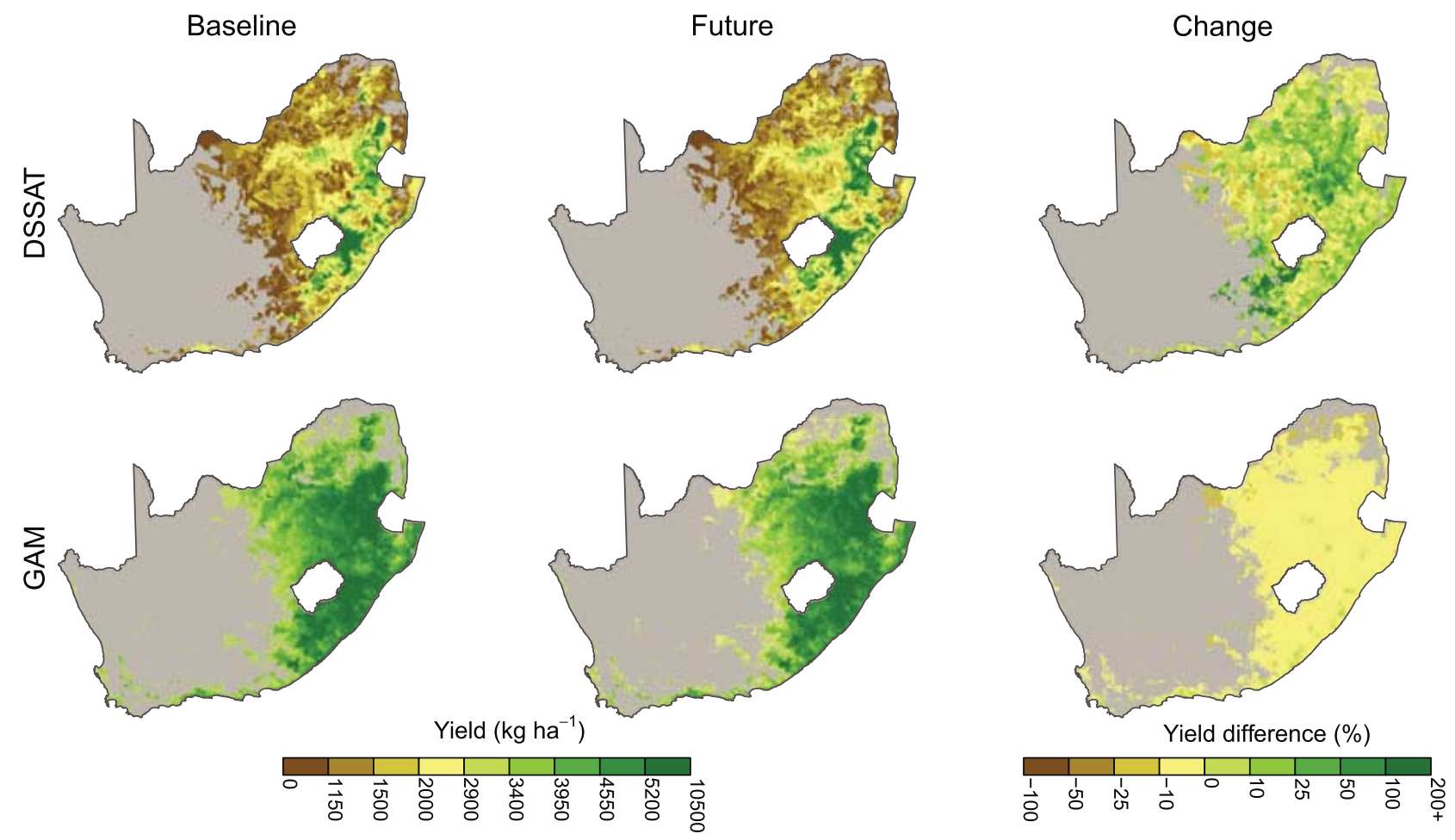

Fig. 4 Decision Support System for Agrotechnology Transfer- (top row) and Generalized Additive Model (GAM)-simulated (bottom row) maize yields for the baseline (left column) and future (middle column) periods, and the differences (right column) between the two expressed as a percentage.

in the interior outside the baseline suitability region (Fig. 5). Along the southern coast where both models showed current wheat suitability, the GAM projected small yield losses $(<10 \%$; Fig. 5), further revealing the GAM's tendency to show losses where DSSAT found gains.

Our findings are consistent with EM-MM comparisons conducted by ecological modelers. Morin \& Thuiller (2009) used two EMs and two MMs to study North American tree species' range shifts in 2100, and found that the EMs projected larger range losses than the MMs. Cheaib et al.'s (2012) projections of French tree species distributions (for 2055) showed the same pattern. Although agricultural impacts researchers use both model classes, they are typically applied separately, and intercomparison studies focus on MM ensembles (Asseng et al., 2013; Rosenzweig et al., 2013; Palosuo et al., 2011; Challinor \& Wheeler, 2008; Müller et al., 2011). However, separate studies suggest that EMs find larger yield losses than MMs (Schlenker \& Lobell, 2010).

There are several potential reasons why EMs tend to project larger climate losses than MMs. First, they assume that the modeled species currently occupies its full potential climate space, even though this may have been historically much broader (Morin \& Thuiller,
2009; Veloz et al., 2012). Regional agricultural impacts studies such as ours are sensitive to this problem. We relied on region-specific crop and climate data to fit models, even though these crops are grown globally under a broad range of climates. For example, if maize distribution data from neighboring countries were available to fit the GAM, it might have shown more tolerance for the hotter, drier conditions along the margins (western through northeastern) of the current growing region (Figs 3 and 4).

Second, EMs are generally fit to climatological variables, but climate adaptation capacity may be better assessed by examining responses to interannual climate variability, rather than changes in climatic means. For instance, a tree species' climate tolerance may be best determined by the degree to which it can adapt phenology to interannual climate variations (Morin \& Thuiller, 2009). In agriculture, a crop's future viability may be more affected by failure rates related to changing interseason variability rather than shifts in long-term means.

Third, it is difficult for EMs to simulate management adaptations that can mitigate climate impacts. In our study, DSSAT models altered planting practices in response to both seasonal and long-term rainfall patterns, thereby simulating a certain level of manage- 
ment adaptation that the GAMs could not. In this case, there was no apparent benefit, and the focus of our study was to understand between-model differences given current management and technology. This EM-MM difference would be more pronounced in a study explicitly focused on climate adaptation potential.

Finally, as EMs do not simulate growth and reproductive processes, they cannot directly account for changes in the plant-climate relationship, such as increasing water-use efficiency and photosynthetic rates with rising $\mathrm{CO}_{2}$ (Leakey, 2009). Cheaib et al. (2012) found $\mathrm{CO}_{2}$ response to be a dominant factor influencing distribution projections for tree species whose range limits are determined by growth rate rather than climatic tolerances; projection discrepancies between EMs and MMs were particularly large for these species.

Although EMs may overestimate climate-induced losses, MMs might underestimate them. One important reason relates to the aforementioned point on plant $-\mathrm{CO}_{2}$ interactions. The response of crops to elevated $\mathrm{CO}_{2}$ is a key uncertainty (Parry et al., 2004; Tubiello et al., 2007), and some studies suggest that current MMs overestimate positive $\mathrm{CO}_{2}$ effects (Ainsworth et al., 2008; Long et al., 2006). We found that elevated $\mathrm{CO}_{2}$ increased DSSAT yield projections by $16 \%$ (maize) and $28 \%$ (wheat). DSSAT's $\mathrm{CO}_{2}$ factor (Eqn 1) increases crop growth rates by $2 \%$ (maize) and $17 \%$ (wheat) for 550 pm concentrations (relative to a 330 ppm baseline). At 660 ppm $(100+$ ppm greater than the levels we used) under well-watered conditions, DSSAT simulates ca. $4 \%$ maize yield increases (developer-reported values Hoogenboom et al., 2012), indicating that the $\mathrm{CO}_{2}-$ related increases we found were primarily due to lower transpiration rates reducing water stress. There is no equivalent reported wheat $\mathrm{CO}_{2}$ sensitivity, but our $\mathrm{CO}_{2}$-related gain was $14 \%$ higher than the mean FACEreported yield increase (Ainsworth et al., 2008), which suggests that this benefit was also due to increased water-use efficiency. We cannot judge how realistic these water-use efficiency gains are, but their size is a major source of difference between DSSAT and GAM projections, which had much smaller $\mathrm{CO}_{2}$ adjustments applied.

Crop MMs may also underestimate temperature sensitivity, particularly during flowering (Rötter et al., 2011). Analyses suggest that recent warming has negatively impacted global maize and wheat yields (Lobell \& Field, 2007), and EMs for major African crops (including maize) show much greater impacts from temperature than precipitation (Schlenker \& Lobell, 2010). African maize trial data show that temperatures $>30{ }^{\circ} \mathrm{C}$ produce strongly negative and nonlinear impacts on yield (Lobell et al., 2011). In DSSAT, growth and grain filling halt at high temperatures, but sterility or mortality does not occur (Ritchie, 1998), thus temperature effects on crop reproduction may not be adequately represented. Low fertilizer parameter settings could also cause MMs to underestimate temperature sensitivity (Schlenker \& Lobell, 2010). Although in this study, higher $\mathrm{N}$ inputs did not increase yield losses under warming (Appendix S4), the results also suggest that DSSAT was most sensitive to rainfall (e.g., very high predicted yields in high rainfall regions; Figs 2 and 4), which was either constant or increasing under the climate scenarios we used. The GAMs may therefore more accurately capture maize and wheat temperature sensitivities, as reflected by their yield loss projections even in areas of increasing rainfall (Figs 2, 4, and 5).

Mechanistic models could also underestimate negative impacts by failing to simulate important biotic limitations (Morin \& Thuiller, 2009), such as weed competition or pest damage. These are major crop growth impediments that are likely to be aggravated by climate change (Tubiello et al., 2007). DSSAT can simulate pest damage, but we could not feasibly implement this for our study. In contrast, EMs implicitly account for these factors because they are encoded in the model training data (Morin \& Thuiller, 2009). The NDVI ${ }_{\text {yield }}$ proxies used to fit GAMs reflected not just climate and soil conditions but also pest prevalence, variable management practices, and other factors that determine actual productivity. Although the impacts of climate change on a crop's biotic interactions are likely to be complex, in some cases, competitors' or predators' niches may simply be shifted to new locations within the existing growing region, or have simple linear responses to climate change, in which case EMs may more realistically reflect potential impacts than MMs.

Given the substantial differences between the two model classes' sensitivities, structures, and projected impacts, it is difficult to say that one class is inherently better than the other for studying climate change impacts. Instead, each may be better at simulating different aspects of crops' -climate responses (e.g., $\mathrm{CO}_{2}$ response by $\mathrm{MMs}$, temperature sensitivity by EMs), while being sensitive to different input data errors, making it advantageous to compare EMs and MMs to obtain a fuller picture of projection uncertainties (Morin \& Thuiller, 2009).

\section{Implications for South African cereal crops}

Our findings differ from previous studies providing nonspatial, country-level projections for South Africa, in that we find smaller negative impacts (GAM median $-3.6 \%$ ) or outright gains (DSSAT median $+6.5 \%$ ) for maize. In comparison, Schlenker \& Lobell (2010) cited 

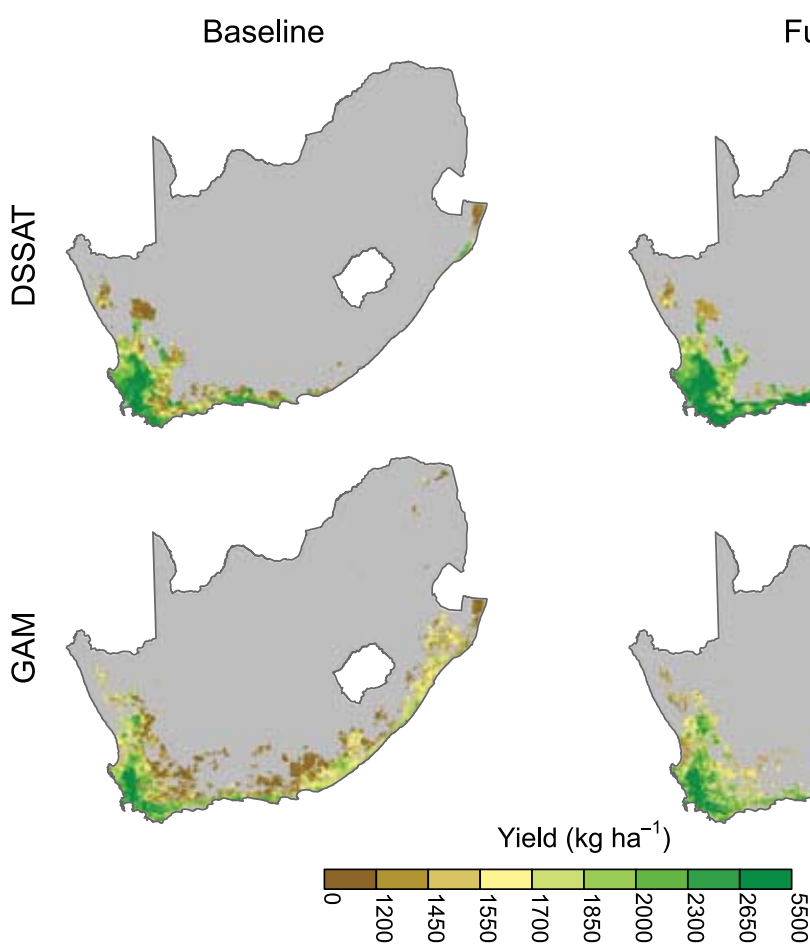

Future
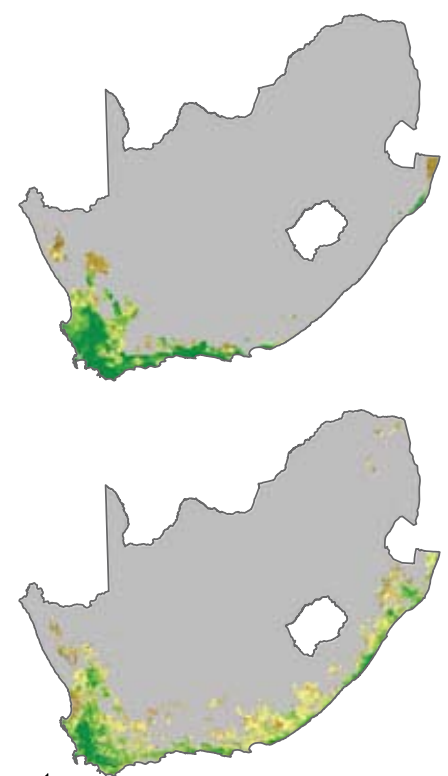

Change
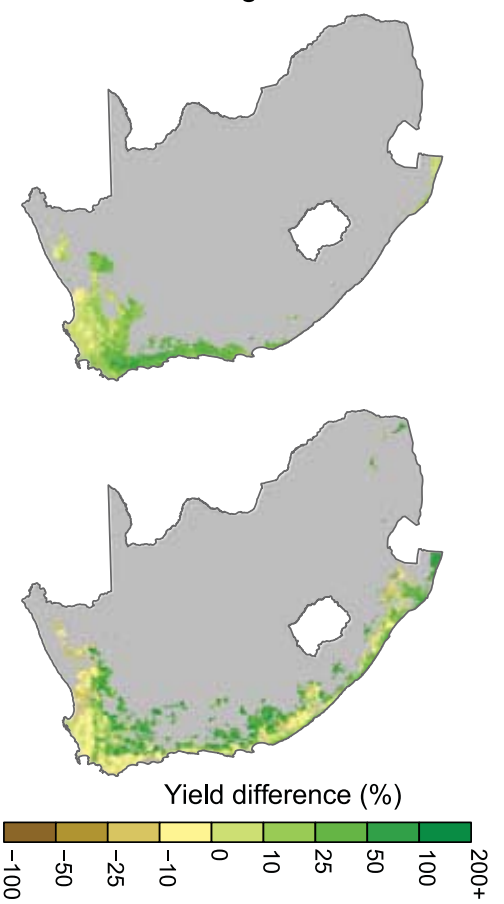

Fig. 5 Decision Support System for Agrotechnology Transfer (DSSAT)- (top row) and Generalized Additive Model (GAM)-simulated (bottom row) wheat yields for the baseline (left column) and future (middle column) periods, and the differences (right column) between the two expressed as a percentage.

three studies (including their own) projecting losses of $10 \%$ or greater (a 4 th showed yield increases, but was considered poorly calibrated). Fischer et al. (2005) in a study of cereal productivity and suitability changes mapped projections for southern Africa showing severe productivity declines under 3 of 4 climate scenarios within South Africa's maize production region. They also found substantial yield losses along the southern coast, where we either found small wheat yield losses (GAM) or substantial gains (DSSAT; Fig. 5).

The difference between our results and the aforementioned studies may be largely due to the CGCM-downscaling technique we used (Hewitson \& Crane, 2006), which produced climate scenarios showing no change or modest precipitation gains over most of South Africa (Fig. 2), which contrasts with the losses projected by the IPCC AR4 for 2080 (IPCC, 2007). Although this downscaling method is well established (Hewitson \& Crane, 2006; Patt et al., 2010; Tadross et al., 2009), understanding the food security implications of our findings in relation to previous estimates is difficult because earlier studies used substantially different climate scenarios. Further assessments are needed to test how different downscaling techniques (including both dynamic and empirical approaches) affect crop impacts projections for this region.

\section{Caveats}

Our study compared just one model per class (EM and $\mathrm{MM}$ ) for each crop; therefore, the strength of our conclusions regarding systematic EM-MM differences is tempered by the small sample size. However, this limitation is partially overcome by the consistency of our results from ecological model intercomparisons, and with the evident differences between EM and MM-based agricultural impacts studies.

Soil data errors could also have biased our results. The soil data were of higher resolution than the global datasets used in comparable regional studies, but they only provided DSSAT's minimum parameter set, which were derived with simplified pedotransfer functions (Estes et al., 2013). Soil fertility was likely overestimated in high rainfall areas (Fig. 2), leading to inflated maize yields by DSSAT, particularly in the eastern highlands (Estes et al., 2013; Appendix S3), which is supported by the asymptotic relationship between $\mathrm{NDVI}_{\text {yield }}$ and rainfall in the GAM model (Appendix S3). DSSAT's seemingly greater sensitivity to rainfall than temperature may also have exaggerated this error. DSSAT also substantially underestimated yields in heavier clay soils due to overestimated WPs (Appendices S1 and S3, Fig. 4). The combination of these two error 
sources makes the DSSAT-NDVI ${ }_{\text {yield }}$ relationship appear to be nonlinear, but neither log transformation nor a second order polynomial model substantially improve the correlation between the two variables (Estes et al., 2013). Furthermore, the relationship between DSSAT and reported yields at the provincial scale is linear.

The GAMs were less reliant on soil parameters and thus less prone to soil-related biases. The GAMs also were unaffected by the assumptions and errors inherent in choosing and calibrating the cultivar coefficients needed by DSSAT (Jones et al., 2003). We were unable to calibrate DSSAT for South African cultivars, which likely increased simulation error, as shown by a study comparing DSSAT and other MMs run with limited calibration (Palosuo et al., 2011). The greater sensitivity of MMs to data and calibration errors is another reason why it is valuable to compare results with EMs.

The GAMs were affected by other weaknesses that could potentially alter interpretations. We followed the novel approach of fitting GAMs to a remotely derived yield proxy, rather than reported yields. A substantial body of work has found that NDVI-derived proxies accurately measure yields at a variety of spatial resolutions (see examples in Estes et al., 2013), which increases our confidence in this approach, but we could only validate this relationship at the provincial scale for maize.

Another limitation was caused by the geographic distribution of the wheat dataset. As our GAM training data were continuous observations $\left(\mathrm{NDVI}_{\text {yield, }}\right.$ as opposed to binary wheat presence/absence data), the model could not be trained under climatically unsuitable conditions because wheat is not grown in those areas. This limitation, combined with the small area of wheat cultivation in South Africa, made the model harder to constrain and less accurate than the maize GAM. Nevertheless, the wheat GAM was useful for comparing to DSSAT in their jointly suitable areas, where the relative differences in their yield projections reflected those seen between the maize models.

\section{Broader implications}

These findings suggest that climate impacts studies focused on food security and agro-ecosystems may be systematically influenced by the class of crop model used. Crop model intercomparison studies (e.g., Rosenzweig et al., 2013) should therefore expand beyond evaluating different MMs to include comparisons between EMs and MMs, where differences may be larger. Because EMs and MMs characterize different aspects of the species-environment relationship (Morin \& Thuiller, 2009) and have different sensitivities, their combined use may provide a fuller picture of uncertainties in crops' climate responses than singleclass ensembles.

\section{Acknowledgements}

We gratefully acknowledge funding from the Princeton Environmental Institutes Grand Challenges Program. We thank Anneliza Collet and Rona Beukes of the National Department of Agriculture, Terry Newby and Dave Turner of the Agricultural Research Council, Fanie Ferreira and Mark Thompson of GeoTerraImage, Eugene du Preez of SiQ, and Lisa Coop of the University of Cape Town for providing data used in developing models, and three reviewers for their helpful feedback.

\section{References}

Ainsworth EA, Leakey ADB, Ort DR, Long SP (2008) FACE-ing the facts: inconsistencies and interdependence among field, chamber and modeling studies of elevated $\left[\mathrm{CO}_{2}\right]$ impacts on crop yield and food supply. New Phytologist, 179, 5-9.

Anonymous (2009) Abstract of Agricultural Statistics. Tech. rep., Department of Agriculture, Pretoria, South Africa.

Asseng S, Ewert F, Rosenzweig C et al. (2013) Uncertainty in simulating wheat yields under climate change. Nature Climate Change. doi: 10.1038/nclimate1916. Advance online publication.

Backlund P, Janetos A, Schimel D (2008) The Effects of Climate Change on Agriculture, Land Resources, Water Resources, and Biodiversity in the United States, Vol 4. USDA, Washington, DC.

Boote K, Allen L Jr, Prasad P, Jones J (2011) Testing effects of climate change in crop models. In: Handbook of Climate Change and Agroecosystems: Impacts, Adaptation, and Mitigation (eds Hillel D, Rosenzweig C), pp. 109-129. Imperial College Press, London.

Bradley B, Estes L, Hole D et al. (2012) Predicting how adaptation to climate change could affect ecological conservation: secondary impacts of shifting agricultural suitability. Diversity and Distributions, 18, 425-437.

Challinor A, Wheeler T (2008) Crop yield reduction in the tropics under climate change: processes and uncertainties. Agricultural and Forest Meteorology, 148, 343-356.

Cheaib A, Badeau V, Boe J et al. (2012) Climate change impacts on tree ranges: model intercomparison facilitates understanding and quantification of uncertainty. Ecology Letters, 15, 533-544.

Christensen JH, Hewitson B, Busuioc A et al. (2007) Regional climate projections. In: Climate Change, 2007: The Physical Science Basis. Contribution of Working Group I to the Fourth Assessment Report of the Intergovernmental Panel on Climate Change, University Press, Cambridge, Chapter 11, pp. 847-940. University Press, Cambridge, UK.

Crespo O, Hachigonta S, Tadross M (2010) Sensitivity of southern African maize yields to the definition of sowing dekad in a changing climate. Climatic Change, 106, 267-283.

Dormann CF (2007) Promising the future? Global change projections of species distributions. Basic and Applied Ecology, 8, 387-397.

Dormann CF, Schymanski SJ, Cabral J et al. (2012) Correlation and process in species distribution models: bridging a dichotomy. Journal of Biogeography, 39, 2119-2131

Estes LD, Bradley BA, Beukes H et al. (2013) Comparing mechanistic and empirical model projections of crop suitability and productivity: implications for ecological forecasting. Global Ecology and Biogeography, 22, 1007-1018.

FAO (2012) FAOStat: Production. Available at: http://faostat.fao.org (accessed 23 March 2012).

Fischer G, Shah M, Tubiello F, van Velhuizen H (2005) Socio-economic and climate change impacts on agriculture: an integrated assessment, 1990-2080. Philosophical Transactions of the Royal Society B: Biological Sciences, 360, 2067-2083.

Fourie A (2009) Better Crop Estimates in South Africa. ArcUser Online. Available at: http://www.esri.com/news/arcuser/0109/crop_estimates.html (accessed 17 January 2012).

Hardy M, Dziba L, Kilian W, Tolmay J (2011) Rainfed farming systems in South Africa. In: Rainfed Farming Systems (eds Tow P, Cooper I, Partridge I, Birch C), pp. 395-432. Springer, The Netherlands.

Hewitson B, Crane R (2006) Consensus between GCM climate change projections with empirical downscaling: precipitation downscaling over South Africa. International Journal of Climatology, 26, 1315-1337. 
Hijmans RJ, Graham CH (2006) The ability of climate envelope models to predict the effect of climate change on species distributions. Global Change Biology, 12, 2272-2281.

Hoogenboom G, Jones J, Wilkens PW et al. (2012) Decision Support System for Agrotechnology Transfer (DSSAT) Version 4.5.0.47. University of Hawaii, Honolulu, HI, USA.

IPCC (2007) IPCC Fourth Assessment Report, Working Group I: Chapter 10. Cambridge University Press, Cambridge and New York.

Jones PG, Thornton PK (2003) The potential impacts of climate change on maize production in Africa and latin america in 2055. Global Environmental Change, 13, 51-59.

Jones J, Hoogenboom G, Porter C, et al. (2003) The DSSAT cropping system model. European Journal of Agronomy, 18, 235-265.

Kimball B (2011) Lessons from FACE: $\mathrm{CO}_{2}$ effects and interactions with water, nitrogen, and temperature. In: Handbook of Climate Change and Agroecosystems: Impacts, Adaptation, and Mitigation (eds Hillel D, Rosenzweig C), pp. 87-107. Imperial College Press, London.

Knox J, Hess T, Daccache A, Wheeler T (2012) Climate change impacts on crop productivity in Africa and South Asia. Environmental Research Letters, 7, 034032.

Leakey ADB (2009) Rising atmospheric carbon dioxide concentration and the future of 44 crops for food and fuel. Proceedings of the Royal Society B: Biological Sciences, 276, 2333-2343.

Lobell DB, Burke MB (2010) On the use of statistical models to predict crop yield responses to climate change. Agricultural and Forest Meteorology, 150, 1443-1452.

Lobell DB, Field CB (2007) Global scale climate-crop yield relationships and the impacts of recent warming. Environmental Research Letters, 2, 014002.

Lobell D, Burke M, Tebaldi C, Mastrandrea M, Falcon W, Naylor R (2008) Prioritizing climate change adaptation needs for food security in 2030. Science, 319, 607-610.

Lobell DB, Bänziger M, Magorokosho C, Vivek B (2011) Nonlinear heat effects on African maize as evidenced by historical yield trials. Nature Climate Change, 1, $42-45$.

Long SP, Ainsworth EA, Leakey ADB, Nosberger J, Ort DR (2006) Food for thought: lower-than-expected crop yield stimulation with rising $\mathrm{CO}_{2}$ concentrations. Science, 312, 1918-1921.

Morin X, Thuiller W (2009) Comparing niche-and process-based models to reduce prediction uncertainty in species range shifts under climate change. Ecology, 90, 1301-1313.

Müller C, Cramer W, Hare WL, Lotze-Campen H (2011) Climate change risks for African agriculture. Proceedings of the National Academy of Sciences, 108, 43134315.

Nakicenovic N, Swart R (2000) Special Report on Emissions Scenarios. Cambridge University Press, Cambridge.

Palosuo T, Kersebaum KC, Angulo C et al. (2011) Simulation of winter wheat yield and its variability in different climates of europe: a comparison of eight crop growth models. European Journal of Agronomy, 35, 103-114.

Parry M, Rosenzweig C, Iglesias A, Fischer G, Livermore M (1999) Climate change and world food security: a new assessment. Global Environmental Change, 1 (Suppl. 9): S51-S67.

Parry ML, Rosenzweig C, Iglesias A, Livermore M, Fischer G (2004) Effects of climate change on global food production under SRES emissions and socio-economic scenarios. Global Environmental Change, 14, 53-67.

Patt AG, Tadross M, Nussbaumer P et al. (2010) Estimating least-developed countries' vulnerability to climate-related extreme events over the next 50 years. Proceedings of the National Academy of Sciences, 107, 1333-1337.

Pongratz J, Lobell DB, Cao L, Caldeira K (2012) Crop yields in a geoengineered climate. Nature Climate Change, 2, 101-105.

Ren J, Chen Z, Zhou Q, Tang H (2008) Regional yield estimation for winter wheat with MODIS-NDVI data in shandong, china. International Journal of Applied Earth Observation and Geoinformation, 10, 403-413.

Rickebusch S, Thuiller W, Hickler T, Araújo MB, Sykes MT, Schweiger O, Lafourcade $\mathrm{B}$ (2008) Incorporating the effects of changes in vegetation functioning and $\mathrm{CO}_{2}$ on water availability in plant habitat models. Biology Letters, 4, 556-559.
Ritchie J (1998) Cereal growth, development and yield. In: Understanding Options for Agricultural Production (eds Hoogenboom G, Thornton P, Singh U, Godwin D, Bowen W), pp. 267-292. Kluwer Academic Publishers, Dortrecht, The Netherlands.

Rosenzweig C, Iglesias A (1998) The use of crop models for international climate change impact assessment. In: Understanding Options for Agricultural Production (eds Tsuji G, Hoogenboom G, Thornton P), pp. 267-292. Kluwer Academic Publishers, Dortrecht, The Netherlands.

Rosenzweig C, Wilbanks T (2010) The state of climate change vulnerability, impacts, and adaptation research: strengthening knowledge base and community. Climatic Change, 100, 103-106.

Rosenzweig C, Jones J, Hatfield J et al. (2013) The agricultural model intercomparison and improvement project (AgMIP): protocols and pilot studies. Agricultural and Forest Meteorology, 170, 166-182.

Rötter RP, Carter TR, Olesen JE, Porter JR (2011) Crop-climate models need an overhaul. Nature Climate Change, 1, 175-177.

Schlenker W, Lobell DB (2010) Robust negative impacts of climate change on African agriculture. Environmental Research Letters, 5, 014010.

Schulze R, Horan M (2010) Methods 1: delineation of South Africa, lesotho and swaziland into quinary catchments. In: Methodological Approaches to Assessing Eco-Hydrological Responses to Climate Change in South Africa (eds Schulze R, Hewitson B, Barichievy K, Tadross M, Kunz R, Horan M, Lumsden T), pp. 63-74. Water Research Commission, Pretoria, South Africa. WRC Report 1562/1/10.

SiQ (2007) Point Frame Sampling: Producer Independent Crop Estimate System (PICES). Available at : http:/ /www.siq.co.za (accessed 11 February 2011)

SIRI (1987) Land type series. In: Memoirs on the Agricultural Natural Resources of South Africa. Soil and Irrigation Research Institute, Department of Agriculture and Water Supply, Pretoria, South Africa.

Tadross M, Suarez P, Lotsch A et al. (2009) Growing-season rainfall and scenarios of future change in Southeast Africa: implications for cultivating maize. Climate Research, 40, 147-161.

Tubiello F, Soussana JF, Howden S (2007) Crop and pasture response to climate change. Proceedings of the National Academy of Sciences, 104, 19686-19690.

Veloz SD, Williams JW, Blois JL, He F, Otto-Bliesner B, Liu Z (2012) No-analog climates and shifting realized niches during the late quaternary: implications for 21st-century predictions by species distribution models. Global Change Biology, 18, 1698-1713.

Wang J, Rich PM, Price KP, Kettle WD (2005) Relations between NDVI, grassland production, and crop yield in the central great plains. GeoCarto International, $20,5$.

Wood SN (2001) mgcv: GAMs and generalized ridge regression for R. R Nerws, 1, $20-25$.

Yee TW, Mitchell ND (1991) Generalized additive models in plant ecology. Journal of Vegetation Science, 2, 587-602.

\section{Supporting Information}

Additional Supporting Information may be found in the online version of this article:

Appendix S1. Datasets.

Appendix S2. Model development and validation.

Appendix S3. Baseline crop model calibration and validation results.

Appendix S4. Additional decision support system for agrotechnology transfer model projections. 